\title{
Prognostic value of a computer-aided diagnosis system involving bone scans among men treated with docetaxel for metastatic castration-resistant prostate cancer
}

Koichi Uemura ${ }^{1+}$, Yasuhide Miyoshi ${ }^{1 *+} \mathbb{D}$, Takashi Kawahara ${ }^{1}$, Shuko Yoneyama', Yusuke Hattori ${ }^{1}$, Jun-ichi Teranishi ${ }^{1}$, Keiichi Kondo ${ }^{1}$, Masatoshi Moriyama ${ }^{2}$, Shigeo Takebayashi ${ }^{3}$, Yumiko Yokomizo ${ }^{4}$, Masahiro Yao ${ }^{4}$, Hiroji Uemura ${ }^{1}$ and Kazumi Noguchi ${ }^{1}$

\begin{abstract}
Background: The bone scan index (BSI), which is obtained using a computer-aided bone scan evaluation system, is anticipated to become an objective and quantitative clinical tool for evaluating bone metastases in prostate cancer. Here, we assessed the usefulness of the BSI as a prognostic factor in patients with metastatic castration-resistant prostate cancer ( $\mathrm{mCRPC}$ ) treated using docetaxel.

Methods: We analyzed 41 patients who received docetaxel for mCRPC. The Bonenavi system was used as the calculation program for the BSI. The utility of the BSI as a predictor of overall survival (OS) after docetaxel was evaluated. The Cox proportional hazards model was used to investigate the association between clinical variables obtained at docetaxel treatment, namely PSA, patient age, liver metastasis, local therapy, hemoglobin (Hb), lactase dehydrogenase (LDH), albumin (Alb), PSA doubling time, and BSI and OS.

Results: The median OS after docetaxel therapy was 17.7 months. Death occurred in 22 (53.7\%) patients; all deaths were caused by prostate cancer. In multivariate analysis, three factors were identified as significant independent prognostic biomarkers for OS after docetaxel; these were liver metastases (yes vs no; HR, 3.681; $p=0.026$ ), Alb (<3.9 vs $\geq 3.9$; HR, 3.776; $p=0.020)$, and BSI (>1\% vs $\leq 1 \% ; \mathrm{HR}, 3.356 ; p=0.037)$. We evaluated the discriminatory ability of our models including or excluding the BSI by quantifying the c-index. The BSI improved the c-index from 0.758 to 0.769 for OS after docetaxel. CRPC patients with a BSI $>1$ had a significantly shorter OS than patients with a BSI $\leq 1 \quad(p=0.029)$.

Conclusions: The BSI, liver metastases and Alb were independent prognostic factors for OS after docetaxel. The BSI might be a useful tool for risk stratification of MCRPC patients undergoing docetaxel treatment.
\end{abstract}

Keywords: Prostate cancer, Castration-resistant, Survival prediction, Bone scan index

\footnotetext{
* Correspondence: miyoyasu@med.yokohama-cu.ac.jp

${ }^{\dagger}$ Equal contributors

'Department of Urology and Renal Transplantation, Yokohama City

University Medical Center, 4-57 Urafune-cho, Minami-ku, Yokohama 232-0024,

Japan

Full list of author information is available at the end of the article
} 


\section{Background}

Huggins and Hodges [1] reported the efficacy of androgen deprivation therapy for advanced prostate cancer in 1941. Although $80-90 \%$ of prostate cancers with metastasis respond to initial androgen ablation therapy, most patients finally develop metastatic castration-resistant prostate cancer (mCRPC) [2, 3]. Patients with mCRPC exhibit progression of systemic symptoms and local complications.

Docetaxel is a survival-prolonging chemotherapy drug used to treat mCRPC patients. Two clinical trials, TAX327 and SWOG99-16, have reported a 20-30 \% relative improvement in overall survival (OS) relative to mitoxantrone, with a median improvement of 2-3 months [4-6].

There have been many reports from Asia and Western countries regarding prognostic factors and risk classification in relation to docetaxel treatment [7-20]. In a previous study, we reported risk factors for $\mathrm{MCRPC}$ patients before docetaxel treatment [18]. In results, pain, visceral metastasis, anemia and progression of bone metastasis were found to be independent prognostic factors for OS after docetaxel. In relation to these prognostic factors "bone metastasis progression" is a subjective variable; thus, an objective and quantitative scoring system for bone metastasis evaluation would potentially be a strong prognostic factor. Recently, a computer-aided diagnosis system (Bonenavi) for bone scans has been developed. This system can be used to calculate the bone scan index (BSI); this provides an objective and quantitative measure of the percentage of the skeleton affected by bone metastases [21]. Mitsui et al. found that patients with a decreased BSI after taxane-based chemotherapy had significantly longer OS than other patients [22]. They also reported that patients with a BSI $\geq 3.0 \%$ had reduced survival relative to men with a BSI $<3.0 \%$ in the same cohort. In our study, we analyzed the relationship between $\mathrm{mCRPC}$ prognosis and clinicopathological factors, including the BSI calculated using the Bonenavi system for OS after docetaxel. The aim of our study was to determine if BSI could be a useful prognostic marker for mCRPC patients undergoing docetaxel treatment.

\section{Methods}

\section{Study design, patients and treatments}

We retrospectively analyzed 41 patients who were treated with docetaxel for mCRPC between 2011 and 2014 at Yokohama City University Medical Center and Yokohama University Hospital. Patient characteristics are listed in Table 1 . Of the patients, 22 had only bone metastasis, 8 had lymph node + bone metastasis, 2 had lung + lymph node + bone metastasis, 3 had lung + bone metastasis, and 6 had liver + lymph node + bone metastasis. The initial median PSA value was $176.0 \mathrm{ng} / \mathrm{ml}$ and the PSA level at docetaxel induction was $56.8 \mathrm{ng} / \mathrm{mL}$. The median BSI was $2.4 \%$ (range, 0.0-12.2\%). All patients had histologically confirmed prostate adenocarcinoma. The 2009 TNM clinical staging system and 2005 International Society of Urologic Pathology Gleason grading system were used [23]. In all patients, clinical stage was evaluated using chest and body computed tomography and bone scans at initial treatment, and before docetaxel treatment.

Each hospital used the same treatment protocol. All patients were initially treated with androgen deprivation therapy (medical or surgical castration with anti-androgen). After initial androgen ablation therapy failed, almost all patients were given anti-androgen withdrawal therapy, subsequent substitution treatment comprising anti-androgen therapy (bicalutamide to flutamide), followed by docetaxel with dexamethasone. Patients were treated with $60 \mathrm{mg} / \mathrm{m}^{2}$ docetaxel IV on day 1 , given over $1 \mathrm{~h}$, every 21 days. All patients received continuous androgen ablation therapy (an LH-RH analogue) and $0.5 \mathrm{mg}$ dexamethasone orally. Treatment was continued until disease progression or unacceptable adverse events occurred.

Some patients received bisphosphonate or denosumab after the development of CRPC. No patients received abiraterone, enzalutamide or cabazitaxel because these drugs were not approved until 2013. For patients at the terminal stage, palliative therapy and pain control with morphine, palliative external beam radiotherapy, and strontium were used as appropriate. Serum PSA levels were measured using the Elecsys PSA Assay (Roche Diagnostics Corp., Basle, Switzerland).

\section{BS}

Bone scan images were obtained within 1 month before or after docetaxel treatment induction. The automated method for analysis of anterior and posterior wholebody bone scan images has been described previously [24]. Each individual hot spot was classified as a metastasis or not a metastasis using an artificial neural network (ANN), and the BSI was calculated as the percentage of the sum of all hot spots classified as bone metastases using the ANN values. To calculate the BSI, we used Bonenavi version 2 (Fujifilm RI Pharma Co. Ltd., Tokyo, Japan; Exini Bone, Exini Diagnostics, Lund, Sweden) [25].

\section{Statistical analysis}

We compared ALP or EOD and BSI levels using Pearson's correlation coefficient. If some factors were found to be correlated with other factors, the correlated factors were not analyzed simultaneously because of multicollinearity. We investigated the usefulness of a BSI as a predictor of survival after docetaxel treatment. The Cox proportional hazards model with stepwise regression analysis was used to investigate the association between clinical variables obtained at docetaxel treatment namely PSA, patient age, liver metastasis, local therapy, hemoglobin $(\mathrm{Hb})$, lactase dehydrogenase (LDH), albumin (Alb), PSA doubling time, 
Table 1 Patient characteristics $(n=41)$

\begin{tabular}{|c|c|}
\hline \multicolumn{2}{|l|}{$\begin{array}{l}\text { Variables before primary androgen } \\
\text { deprivation therapy }\end{array}$} \\
\hline Median initial PSA, ng/mL (range) & $176.0(4.2-6500.0)$ \\
\hline \multicolumn{2}{|l|}{ Gleason scores, n (\%) } \\
\hline $6-7$ & $4(9.8 \%)$ \\
\hline $8-10$ & $37(90.2 \%)$ \\
\hline \multicolumn{2}{|l|}{ Clinical T, n (\%) } \\
\hline$\leq \mathrm{T} 3$ & $32(78.0 \%)$ \\
\hline T4 & $9(22.0 \%)$ \\
\hline \multicolumn{2}{|l|}{ Clinical N, n (\%) } \\
\hline No & $14(34.1 \%)$ \\
\hline N1 & $27(65.9 \%)$ \\
\hline \multicolumn{2}{|l|}{ Clinical M, n (\%) } \\
\hline Mo & $12(29.3 \%)$ \\
\hline M1a & $5(12.2 \%)$ \\
\hline M1b & $21(51.2 \%)$ \\
\hline M1c & $3(7.3 \%)$ \\
\hline \multicolumn{2}{|l|}{$\mathrm{EOD}, n(\%)$} \\
\hline 0 & $17(41.5 \%)$ \\
\hline 1 & $4(9.8 \%)$ \\
\hline 2 & $4(9.8 \%)$ \\
\hline 3 & $7(17.1 \%)$ \\
\hline 4 & $9(22.0 \%)$ \\
\hline \multicolumn{2}{|l|}{$\begin{array}{l}\text { Variables at docetaxel therapy } \\
\text { induction }\end{array}$} \\
\hline Median PSA, ng/mL (range) & $56.8(0.2-4715.0)$ \\
\hline $\begin{array}{l}\text { Median PSA doubling time, } \\
\text { months (range) }\end{array}$ & $1.4(-3.8-47.1)$ \\
\hline Median LDH, IU/L (range) & $225(135-1129)$ \\
\hline Median Hb, g/dL (range) & $11.7(8.1-13.7)$ \\
\hline Median Alb, g/dL (range) & $3.9(2.4-4.7)$ \\
\hline Median ALP, IU/L (range) & $278(135-3296)$ \\
\hline Median age, years (range) & $73(48-81)$ \\
\hline \multicolumn{2}{|l|}{$\mathrm{EOD}, n(\%)$} \\
\hline 0 & $1(2.4)$ \\
\hline 1 & $10(24.4)$ \\
\hline 2 & $13(31.7)$ \\
\hline 3 & $11(26.8)$ \\
\hline 4 & $6(14.6)$ \\
\hline Median BSI, \% (range) & $2.4(0.0-12.2)$ \\
\hline $\mathrm{BSI} \leq 1 \%, n(\%)$ & $18(43.9 \%)$ \\
\hline $\mathrm{BSI}>1 \%, n(\%)$ & $23(56.1 \%)$ \\
\hline \multicolumn{2}{|l|}{ Liver metastasis, $n$ (\%) } \\
\hline Yes & $6(14.96 \%)$ \\
\hline No & 35 (85.4 \%) \\
\hline
\end{tabular}

Table 1 Patient characteristics $(n=41)$ (Continued)

Local therapy (prostatectomy

or radiation), $n(\%)$

No $\quad 36$ (87.8\%)

$5(12.2 \%)$

PSA prostate-specific antigen, $L D H$ lactate dehydrogenase, $H b$ hemoglobin, $A / b$ albumin, $B S I$ bone scan index

BSI and survival. The cutoff point for PSA, patient age, $\mathrm{Hb}$, $\mathrm{LDH}, \mathrm{Alb}$ and PSADT were determined using the median value of each variable. The cutoff point for the BSI was set at $1.0 \%$ according to a report by Ulmert and colleagues [24].

Relative risks and $95 \%$ confidence intervals were derived. The C-index was used regarding the discriminatory ability of our models.

To calculate the PSA doubling time (PSADT), two consecutive PSA values, spaced 1 month apart after docetaxel induction therapy, were used. PSADT was calculated using the natural log of 2 (0.693) divided by the slope of the relationship between the log of PSA and the time of PSA measurement for each patient [26].

The Kaplan-Meier product-limit estimator was used to estimate the survival distribution. The log-rank test was used for analysis of the survival differences.

All tests were two-sided, and the significance level was fixed at alpha $=0.05$. All analyses were conducted using IBM SPSS Statistics software for Windows, version 22 (IBM Corp., Armonk, NY, USA) and the R stats package ( $R$ Foundation for Statistical Computing, Vienna, Austria).

The experimental procedures were conducted in accordance with the ethical standards of the Helsinki Declaration. This study was approved by the institutional review board of Yokohama City University Medical Center. Informed consent to participate in the study were obtained from participants

\section{Results}

In our cohort, death occurred in 22 patients (53.7\%); all deaths were caused by prostate cancer. The median OS after docetaxel therapy was 17.7 (95\% confidential interval [CI]: 10.6-24.9; range, 1.7-51.0) months (Fig. 1).

The correlation of EOD classification and the BSI is shown in Fig. 2. There was a significant correlation between EOD and the BSI $(r=0.693)$. A significant correlation between serum alkaline phosphatase (ALP) levels and the BSI was also observed ( $r=0.643$, Fig. 3). Because of the strong correlations, we did not analyze the BSI, serum ALP levels, and EOD in multivariate analysis simultaneously owing to multicollinearity.

In multivariate analysis, three factors were identified as independent prognostic biomarkers for OS after docetaxel therapy as follows: liver metastases (yes vs no; HR, 3.681; 95 \% CI, 1.166-11.616; $p=0.026)$, Alb $(<3.9$ g/dL 


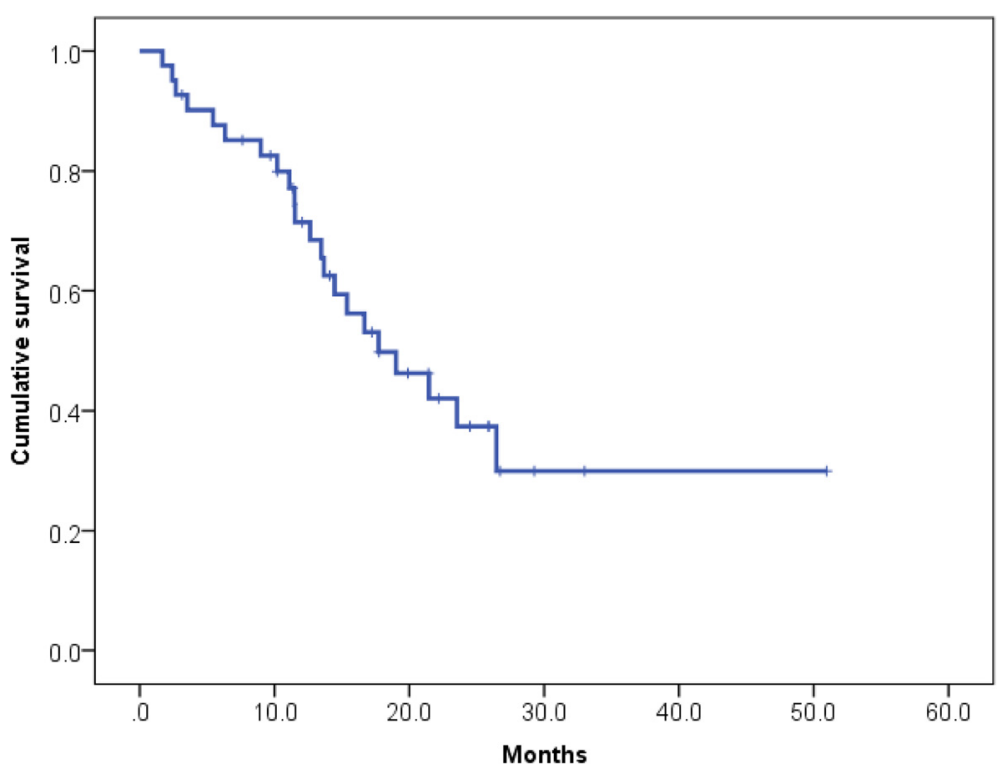

Fig. 1 Kaplan-Meier curve for overall survival (OS) after docetaxel induction therapy. The median OS after docetaxel was 17.7 months

vs $\geq 3.9$ g/dL; HR, 3.776; $95 \%$ CI, 1.238-11.516; $p=0.020$ ), and BSI (>1 \% vs $\leq 1 \%$; HR, 3.356; $95 \%$ CI, 1.078-10.453; $p=0.037$ ) (Table 2).

We evaluated the discriminatory ability of our models by quantifying the c-index. The c-index in our model including the BSI was 0.769 in the prediction of OS after docetaxel therapy. We also analyzed the discriminatory ability of the model excluding BSI by quantifying the c-index. The c-index of the model excluding BSI was 0.758 for the prediction of OS. In predicting OS, the c-index of the model including the BSI was higher relative to the model excluding the BSI.

We compared the survival probability by BSI categories. The median OS was 26.5 months in patients with a BSI

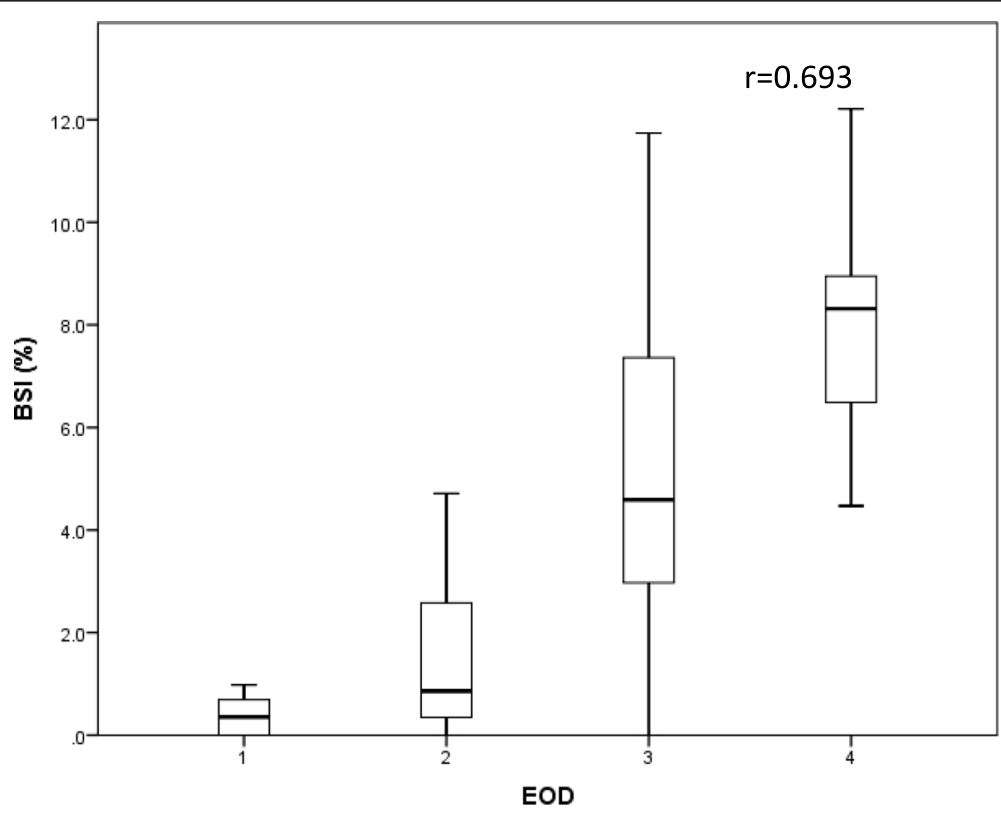

Fig. 2 Correlation of EOD classification and the BSI. Box plots indicate the first and third quartiles. The band inside the box shows the median. Lines extending vertically from the boxes (whiskers) indicate variability outside the upper and lower quartiles. There was a significant correlation between EOD and the BSI $(r=0.693)$. BSI; bone scan index, EOD; extent of disease on bone scan 


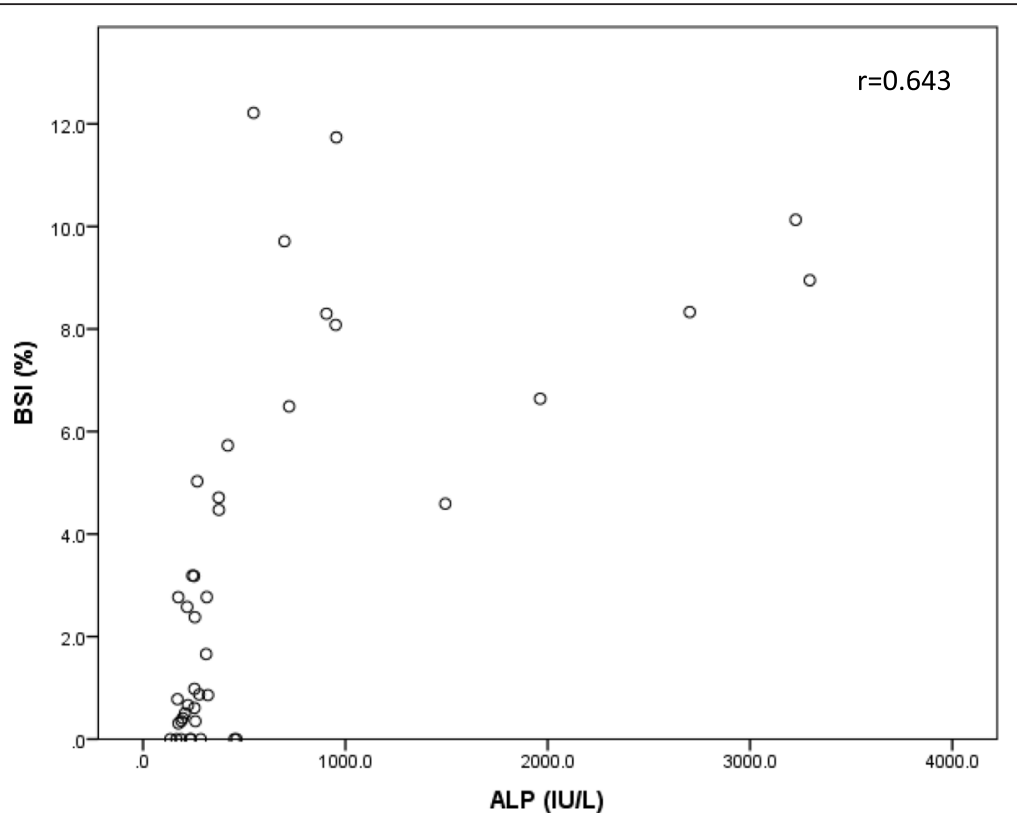

Fig. 3 Correlation of ALP levels and the BSI. There was a strong correlation between serum ALP levels and the BSI ( $r=0.643)$. ALP; alkaline phosphatase, BSI; bone scan index

$\leq 1$ and 15.4 months in patients with a BSI $>1(p=0.029)$. Patients with a BSI $>1$ had a significantly shorter OS than patients with BSI $\leq 1$ (Fig. 4).

We stratified the patients into two cohorts with low risk (0-1 risk factor present) and high risk (2-3 risk factors present). The risk factors in each risk group were shown in Table 3. We found a statistically significant difference in OS after docetaxel treatment among risk groups (Fig. $5 ; p<0.000$ ).

\section{Discussion}

In this study, we reported the usefulness of BSI which calculated by computer-aided diagnosis system involving bone scans as prognostic biomarker in CRPC patients, although the routine use of bone scan in CRPC treatments remains controversial. Recently, clinical significance of imaging in CPRC treatments have been increasing and developing rapidly. Several studies demonstrated the usefulness of the PET/CT both for restaging and for assessing the response to treatment in CRPC patients [27-29].

Several groups have reported prognostic models for the survival of patients with castration-resistant prostate cancer. Armstrong and colleagues reported that a decrease of $30 \%$ in PSA level, visceral metastasis, anemia and bone scan progression were independent prognostic factors in docetaxel-treated patients with CRPC [20]. We have also

Table 2 Univariate and multivariate analysis of overall survival after the administration of docetaxel

\begin{tabular}{|c|c|c|c|c|c|c|c|c|}
\hline \multirow{3}{*}{$\begin{array}{l}\text { Variables at docetaxel } \\
\text { induction }\end{array}$} & \multicolumn{4}{|c|}{ Univariate analysis } & \multicolumn{4}{|c|}{ Multivariate analysis } \\
\hline & \multirow[t]{2}{*}{$p$ value } & \multirow{2}{*}{$\begin{array}{l}\text { Hazard } \\
\text { ratio }\end{array}$} & \multicolumn{2}{|c|}{$95.0 \% \mathrm{Cl}$} & \multirow[t]{2}{*}{$p$ value } & \multirow{2}{*}{$\begin{array}{l}\text { Hazard } \\
\text { ratio }\end{array}$} & \multicolumn{2}{|c|}{$95.0 \% \mathrm{Cl}$} \\
\hline & & & Lower & Upper & & & Lower & Upper \\
\hline PSA ( $\geq 56.8 \mathrm{ng} / \mathrm{mL}$ vs <56.8) & 0.115 & 1.991 & 0.845 & 4.693 & 0.894 & 0.929 & 0.317 & 2.729 \\
\hline Age(>73 vs $\leq 73)$ & 0.623 & 0.810 & 0.349 & 1.879 & 0.944 & 0.964 & 0.343 & 2.704 \\
\hline Liver mets (yes vs no) & 0.239 & 1.825 & 0.670 & 4.969 & 0.026 & 3.681 & 1.166 & 11.616 \\
\hline Local therapy (yes vs no) & 0.137 & 0.218 & 0.029 & 1.624 & 0.206 & 0.213 & 0.019 & 2.339 \\
\hline $\mathrm{Hb}(<11.7 \mathrm{~g} / \mathrm{dL}$ vs $\geq 11.7)$ & 0.072 & 0.457 & 0.194 & 1.072 & 0.887 & 1.073 & 0.404 & 2.850 \\
\hline LDH (>225 IU/L vs $\leq 225)$ & 0.045 & 2.385 & 1.019 & 5.578 & 0.078 & 2.500 & 0.903 & 6.915 \\
\hline Alb $(<3.9 \mathrm{~g} / \mathrm{dL}$ vs $\geq 3.9)$ & 0.001 & 5.965 & 1.987 & 17.908 & 0.020 & 3.776 & 1.238 & 11.516 \\
\hline PSADT $(\leq 1.4$ months vs $>1.4)$ & 0.123 & 1.971 & 0.832 & 4.668 & 0.888 & 1.075 & 0.392 & 2.948 \\
\hline BSI (>1 \% vs $\leq 1 \%)$ & 0.035 & 2.673 & 1.072 & 6.661 & 0.037 & 3.356 & 1.078 & 10.453 \\
\hline
\end{tabular}

PSA prostate-specific antigen, PSADT PSA doubling time, $\mathrm{Hb}$ hemoglobin, $\mathrm{LDH}$ lactate dehydrogenase, $A / b$ albumin, $B S I$ bone scan index, $L$ iver mets liver metastasis The normal ranges of $\mathrm{Hb}, \mathrm{LDH}$ and Alb were $11.3-14.5 \mathrm{~g} / \mathrm{dL}, 116-199 \mathrm{IU} / \mathrm{L}$ and $4.2-5.4 \mathrm{~g} / \mathrm{dL}$, respectively 


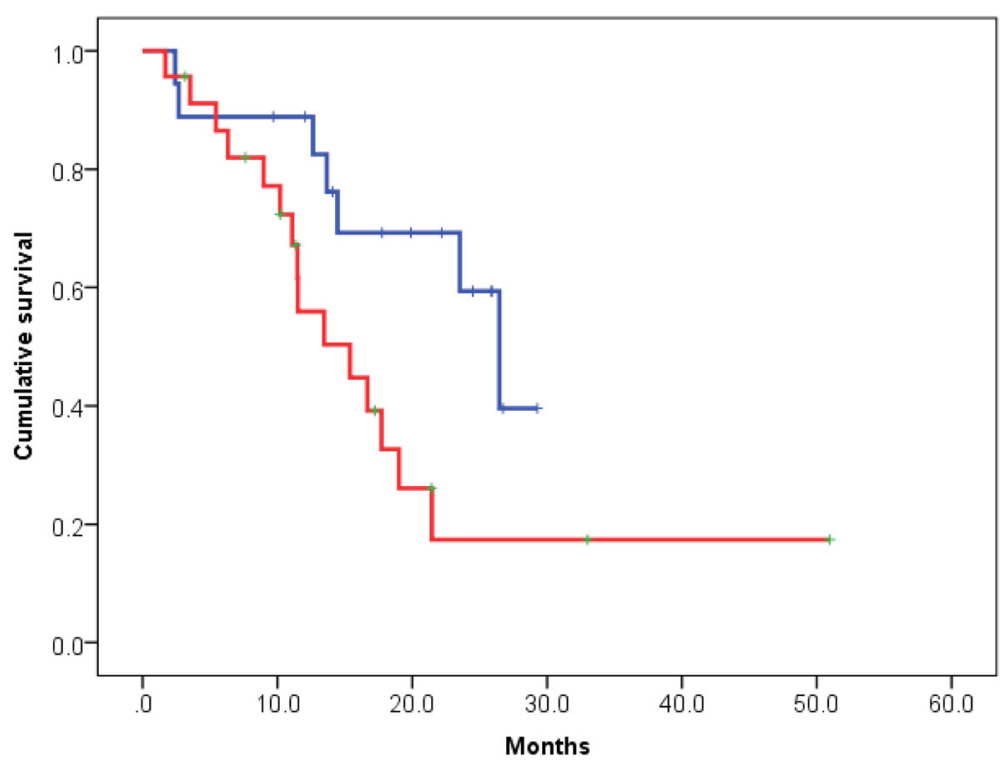

Fig. 4 Kaplan-Meier curve for overall survival (OS) after docetaxel induction therapy according to the bone scan index (BSI). The blue line indicates survival for patients with a BSI $\leq 1(n=18)$ and the red line indicates survival for patients with a BSI $>1(n=23)$. The median OS of patients with a BSI $\leq 1$ and a BSI $>1$ was 26.5 and 15.4 months, respectively $(p=0.029)$

previously described the risk factors for mCRPC patients before docetaxel treatment [18]. In results, pain, visceral metastasis, anemia and bone metastasis progression were independent prognostic factors for OS after docetaxel [18]. Because $>80 \%$ of $\mathrm{mCRPC}$ patients have bone metastases [4, 5], more attention should be given to accurate evaluation of bone metastases in the consideration of prognosis. The extent of disease (EOD) score suggested by Soloway et al. [30] was used for the evaluation of bone metastasis in prostate cancer. Based on the number or extent of the metastases, the scans were divided into the following five grades according to the EOD on bone scan [30]: 0) normal or abnormal as a result of benign bone disease; 1) $<6$ bony metastases, each of which is $<50 \%$ of the size of a vertebral body (one lesion that was approximately the size of a vertebral body was counted as two lesions); 2) 6-20 bone metastases, sized as described above; 3) > 20 metastases but fewer than seen in a "superscan"; and 4) superscan or its equivalent (i.e., $>75 \%$ of the ribs, vertebrae and pelvic bones). Previously, we analyzed

Table 3 Distribution of risk factors classified by risk group

\begin{tabular}{lll}
\hline & Low risk & High risk \\
\hline Risk factors, $n$ & $0-1$ & $2-3$ \\
Patients, $n(\%)$ & $25(61.0 \%)$ & $16(39.0 \%)$ \\
Alb, $<3.9 \mathrm{~g} / \mathrm{dL}, n(\%)$ & $6(14.6 \%)$ & $14(34.1 \%)$ \\
$\mathrm{BSI},>1 \%, n(\%)$ & $9(22.0 \%)$ & $14(34.1 \%)$ \\
Liver mets, yes, $n(\%)$ & $1(2.4 \%)$ & $5(12.2 \%)$ \\
\hline
\end{tabular}

There were no patients with $>3$ risk factors

Alb albumin, BSI bone scan index, Liver mets liver metastasis the relationship between prostate cancer outcomes and pretreatment clinical factors, and developed a prognostic survival model for patients with bone metastatic hormonenaive prostate cancer [31]. In that model, the EOD score was a strong prognostic factor for survival.

Although the EOD score has important prognostic information, it is a subjective and semi-quantitative parameter. For a more accurate and convenient method for bone metastases evaluation, objective and quantitative markers are required. Accurate evaluation of bone metastases would lead to an appropriate prediction of prostate cancer survival probability, and would be valuable for patient counseling.

It is anticipated that a BSI that uses a computer-aided diagnosis system for bone scans will become an objective and quantitative clinical tool for evaluating bone metastatic prostate cancer. The BSI has been reported as being useful as a survival predictor among men with prostate cancer with various conditions such as hormone-naïve prostate cancer or CRPC [22, 32-38].

In patients with CRPC, the usefulness of the BSI as a prognostic marker has been reported. Mitsui et al. found that patients with a decreased BSI after taxane-based chemotherapy had significantly longer OS than other patients [22]. They also reported that patients with a BSI $\geq 3.0$ had reduced survival relative to men with a BSI $<3.0$ in the same cohort. Koboteh et al. also reported that patients with a decreased BSI after docetaxel had a better prognosis than other patients [35]. Dennis et al. reported that a change in BSI from baseline to 3-6 months after treatment for CRPC may provide prognostic information 


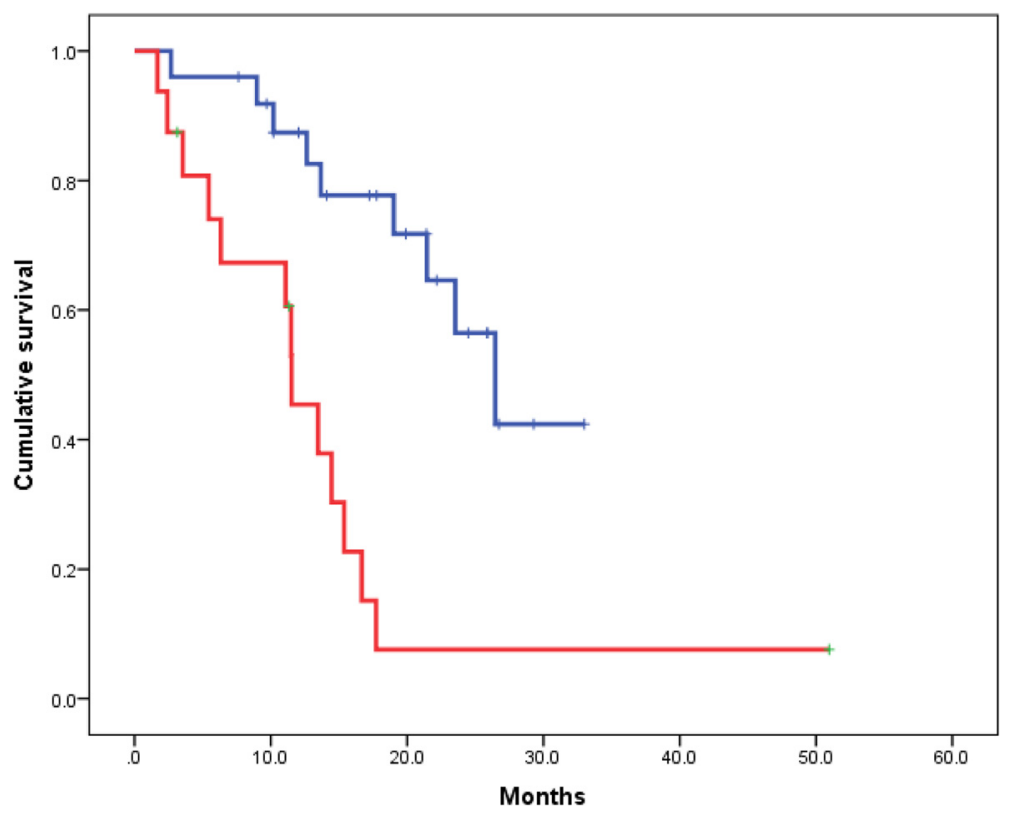

Fig. 5 Kaplan-Meier curve for overall survival (OS) after docetaxel induction therapy according to risk group. We stratified the patients into two cohorts with low risk (0-1 risk factor present) and high risk (2-3 risk factors present). The blue line indicates survival for patients with low risk $(n=25)$ and the red line indicates survival for patients with high risk $(n=16)$. The median OS of patients with low risk and high risk was 26.5 and 11.5 months, respectively $(p<0.000)$. The risk factors in each risk group were shown in Table 3

[33]. Armstrong et al. reported that the BSI, and change in the BSI over time, were independently associated with OS in patients with $\mathrm{mCRPC}$ in a tasquinimod treatment trial [32]. Although some studies have demonstrated the usefulness of the BSI, unfortunately few have included significant clinical information such as blood data and visceral metastasis. In previous studies, patient age and blood data such as serum $\mathrm{Hb}$, alkaline phosphatase, LDH and CRP levels have been reported as predictive factors for patients with prostate cancer [39-41]. In our study, we analyzed the correlations between survival and clinical factors including variables at docetaxel induction therapy (PSA, patient age, liver metastasis, local therapy, $\mathrm{Hb}, \mathrm{LDH}, \mathrm{Alb}$, PSA doubling time, and BSI) using the Cox proportional hazards regression model. EOD classifications and serum ALP level were significantly associated with the BSI value; EOD and serum ALP level were not included in the multivariate analysis because of multicollinearity. Three factors were identified as independent prognostic biomarkers for OS after docetaxel therapy as follows: liver metastases, Alb and BSI. Because the BSI has continuous covariations, it is better suited and accurate in the prediction of individual patient prognosis relative to EOD classifications.

In addition, we evaluated the discriminatory ability of our models including or excluding the BSI by quantifying the c-index. The BSI improved the c-index from 0.758 to 0.769 in predicting OS after docetaxel therapy. Median OS after docetaxel was 26.5 months in patients with a BSI $\leq 1$ and the median OS after docetaxel was
15.4 months in patients with a BSI $>1 \quad(p=0.029)$. Patients with a BSI $>1$ had a significantly shorter OS than patients with a BSI $\leq 1$.

Recently, there has been rapid development in the treatment of CRPC. In the United States and other Western countries, some new effective agents for CRPC have been approved, including docetaxel, cabazitaxel, radium-223 dichloride, sipuleucel-T, abiraterone and enzalutamide [4, 42-47]. Unfortunately, treatment for CRPC in Japan was very limited until 2013 (cabazitaxel, abiraterone and enzalutamide were approved in 2014), even though docetaxel was approved in 2008 [48]. Thus, in our study, none of the patients received cabazitaxel, sipuleucel-T, abiraterone or enzalutamide. These agents could improve the survival of patients with CRPC, and our model could underestimate the prognosis when these new agents were used for CRPC.

Thus, the first limitation of our study is that our models were developed using data from the "docetaxel era." For more accurate prediction of prognosis in patients with prostate cancer in the "post-docetaxel era," more recently collected data are needed. The second limitation is the fact that patients enrolled had various health statuses and complications. Our models considered neither health status nor patient complications that may influence prostate cancer treatment outcomes [49-51]. Patients with prostate cancer are much older than those with other malignancies. Health status and complications should be classified in the rating score and included as predictive factors in the prognostic model. Bone pain at diagnosis is 
also a strong predictor of survival [51]. Unfortunately, data regarding pain at baseline were not available in this study. Moreover, no information was available on the number of patients received bisphosphonate or denosumab after the development of CRPC. Bisphosphonate or denosumab showed significant effect for reducing the skeletal-related events and improving progression-free survival although these agents except clodronate has not been shown to improve overall survival in randomized phase 3 controlled trial $[52,53]$. Finally, our population was small and observation periods were relatively short. Evaluation of larger patient populations and long observations are warranted to establish the usefulness of the BSI as a prognostic factor. Although some study limitations exist, the BSI before treatment might be useful as a prognostic biomarker for hormone-naïve bone metastatic prostate cancer.

\section{Conclusions}

In conclusion, we evaluated the prognostic value of a computer-aided diagnosis system (Bonenavi) for bone scans in patients who received docetaxel treatment for mCRPC. The BSI (calculated using Bonenavi), Alb and liver metastases were independent prognostic factors for OS after docetaxel therapy. BSI might be a useful tool for risk stratification of patients with $\mathrm{mCRPC}$ undergoing docetaxel treatment.

\section{Abbreviations \\ iPSA: Initial prostate-specific antigen; GS: Gleason scores; PSADT: PSA doubling time; LDH: Lactate dehydrogenase; Hb: Hemoglobin; Alb: Albumin; BSI: Bone scan index.}

\section{Competing interests}

The authors have no competing interests to declare.

\section{Authors' contributions}

Dr. YM, designed the study. Dr. YM and Dr. KU contributed to statistical analysis and wrote the manuscript. Dr. TK supported the statistical analysis. Dr. SY, Dr. YH, Dr. JT, Dr. KK, Dr. MM, Prof. ST, Dr. YY, Prof. MY, Dr. HU and Prof. KN contributed to collection of the clinical data. All authors have read and approved the final manuscript.

\section{Acknowledgments}

This work was supported by a Grant-in-Aid for Scientific Research from Japan. This work was supported by a MEXT/JSPS KAKENHI grant.

\section{Author details}

'Department of Urology and Renal Transplantation, Yokohama City University Medical Center, 4-57 Urafune-cho, Minami-ku, Yokohama 232-0024, Japan. ${ }^{2}$ Department of Urology, Yokohama Municipal Citizen's Hospital, Yokohama, Japan. ${ }^{3}$ Department of Radiology, Yokohama City University Medical Center, Yokohama, Japan. ${ }^{4}$ Department of Urology, Yokohama City University Graduate School of Medicine, Yokohama, Japan.

Received: 22 August 2015 Accepted: 10 February 2016

Published online: 16 February 2016

\section{References}

1. Huggins C, Hodges CV. Studies on prostatic cancer I: the effect of castration, of estrogen, and of androgen injection on serum phosphatases in metastatic carcinoma of the prostate. Cancer Res. 1941;1:293-7.

2. Small EJ, Vogelzang NJ. Second-line hormonal therapy for advanced prostate cancer: a shifting paradigm. J Clin Oncol. 1997;15(1):382-8.
3. Oh WK, Kantoff PW. Management of hormone refractory prostate cancer: current standards and future prospects. J Urol. 1998;160(4):1220-9.

4. Petrylak DP, Tangen CM, Hussain MH, Lara Jr PN, Jones JA, Taplin ME, Burch PA, Berry D, Moinpour C, Kohli M et al. Docetaxel and estramustine compared with mitoxantrone and prednisone for advanced refractory prostate cancer. $\mathrm{N}$ Engl J Med. 2004:351(15):1513-20.

5. Tannock IF, de Wit R, Berry WR, Horti J, Pluzanska A, Chi KN, Oudard S, Theodore C, James ND, Turesson I et al. Docetaxel plus prednisone or mitoxantrone plus prednisone for advanced prostate cancer. N Engl J Med. 2004;351(15):1502-12.

6. Armstrong AJ. Docetaxel for advanced prostate cancer: how early to start? Lancet Oncol. 2015;16(7):741-2.

7. Linton A, Pond G, Clarke S, Vardy J, Galsky M, Sonpavde G. Glasgow prognostic score as a prognostic factor in metastatic castration-resistant prostate cancer treated with docetaxel-based chemotherapy. Clin Genitourin Cancer. 2013;11(4):423-30.

8. Matsuyama H, Shimabukuro T, Hara I, Kohjimoto Y, Suzuki K, Koike H, Uemura $H$, Hayashi T, Ueno M, Kodaira K et al. Combination of hemoglobin, alkaline phosphatase, and age predicts optimal docetaxel regimen for patients with castration-resistant prostate cancer. Int J Clin Oncol. 2014; 19(5):946-54.

9. Shiota M, Yokomizo A, Adachi T, Koga H, Yamaguchi A, Imada K, Takeuchi A, Kiyoshima K, Inokuchi J, Tatsugami K et al. The oncological outcomes and risk stratification in docetaxel chemotherapy for castration-resistant prostate cancer. Jpn J Clin Oncol. 2014;44(9):860-7.

10. Thalgott M, Rack B, Eiber M, Souvatzoglou M, Heck MM, Kronester C, Andergassen U, Kehl V, Krause BJ, Gschwend JE et al. Categorical versus continuous circulating tumor cell enumeration as early surrogate marker for therapy response and prognosis during docetaxel therapy in metastatic prostate cancer patients. BMC Cancer. 2015;15:458.

11. Miura N, Numata K, Kusuhara Y, Shirato A, Hashine K, Sumiyoshi Y. Docetaxel-prednisolone combination therapy for Japanese patients with hormone-refractory prostate cancer: a single institution experience. Jpn J Clin Oncol. 2010;40(11):1092-8.

12. Miyake H, Sakai I, Terakawa T, Harada K, Fujisawa M. Oncological outcome of docetaxel-based chemotherapy for Japanese men with metastatic castration-resistant prostate cancer. Urol Oncol. 2013;31(6):733-8.

13. Pastina I, Giovannetti E, Chioni A, Sissung TM, Crea F, Orlandini C, Price DK, Cianci C, Figg WD, Ricci S et al. Cytochrome 450 1B1 (CYP1B1) polymorphisms associated with response to docetaxel in Castration-Resistant Prostate Cancer (CRPC) patients. BMC Cancer. 2010;10:511.

14. Pond GR, Armstrong AJ, Wood BA, Leopold L, Galsky MD, Sonpavde G. Ability of C-reactive protein to complement multiple prognostic classifiers in men with metastatic castration resistant prostate cancer receiving docetaxel-based chemotherapy. BJU Int. 2012;110(11 Pt B):E461-468.

15. Qu YY, Dai B, Kong YY, Ye DW, Yao XD, Zhang SL, Ma CG, Yang WY. Prognostic factors in Chinese patients with metastatic castration-resistant prostate cancer treated with docetaxel-based chemotherapy. Asian J Androl. 2013;15(1):110-5.

16. Strijbos MH, Gratama JW, Schmitz PI, Rao C, Onstenk W, Doyle GV, Miller MC, de Wit R, Terstappen LW, Sleijfer S. Circulating endothelial cells, circulating tumour cells, tissue factor, endothelin-1 and overall survival in prostate cancer patients treated with docetaxel. Eur J Cancer. 2010;46(11):2027-35.

17. Domingo-Domenech J, Fernandez PL, Filella X, Martinez-Fernandez A, Molina R, Fernandez E, Alcaraz A, Codony J, Gascon P, Mellado B. Serum HER2 extracellular domain predicts an aggressive clinical outcome and biological PSA response in hormone-independent prostate cancer patients treated with docetaxel. Ann Oncol. 2008;19(2):269-75.

18. Kawahara T, Miyoshi Y, Sekiguchi Z, Sano F, Hayashi N, Teranishi J, Misaki H, Noguchi K, Kubota Y, Uemura H. Risk factors for metastatic castration-resistant prostate cancer (CRPC) predict long-term treatment with docetaxel. PLoS One. 2012;7(10):e48186.

19. Berthold DR, Pond GR, Roessner M, de Wit R, Eisenberger M, Tannock Al, investigators TAX. Treatment of hormone-refractory prostate cancer with docetaxel or mitoxantrone: relationships between prostate-specific antigen, pain, and quality of life response and survival in the TAX-327 study. Clin Cancer Res. 2008;14(9):2763-7.

20. Armstrong AJ, Tannock IF, de Wit R, George DJ, Eisenberger M, Halabi $\mathrm{S}$. The development of risk groups in men with metastatic castrationresistant prostate cancer based on risk factors for PSA decline and survival. Eur J Cancer. 2010;46(3):517-25. 
21. Wakabayashi H, Nakajima K, Mizokami A, Namiki M, Inaki A, Taki J, Kinuya S Bone scintigraphy as a new imaging biomarker: the relationship between bone scan index and bone metabolic markers in prostate cancer patients with bone metastases. Ann Nucl Med. 2013;27(9):802-7.

22. Mitsui $Y$, Shiina $H$, Yamamoto $Y$, Haramoto $M$, Arichi $N$, Yasumoto $H$, Kitagaki $\mathrm{H}$, Igawa M. Prediction of survival benefit using an automated bone scan index in patients with castration-resistant prostate cancer. BJU Int. 2012; 110(11 Pt B):E628-634.

23. Epstein Jl, Allsbrook Jr WC, Amin MB, Egevad LL, Committee IG. The 2005 International Society of Urological Pathology (ISUP) Consensus Conference on Gleason Grading of Prostatic Carcinoma. Am J Surg Pathol. 2005;29(9):1228-42.

24. Ulmert D, Kaboteh R, Fox JJ, Savage C, Evans MJ, Lilja H, Abrahamsson PA, Bjork T, Gerdtsson A, Bjartell A et al. A novel automated platform for quantifying the extent of skeletal tumour involvement in prostate cancer patients using the Bone Scan Index. Eur Urol. 2012;62(1):78-84.

25. Koizumi M, Wagatsuma K, Miyaji N, Murata T, Miwa K, Takiguchi T, Makino T, Koyama M. Evaluation of a computer-assisted diagnosis system, BONENAVI version 2, for bone scintigraphy in cancer patients in a routine clinical setting. Ann Nucl Med. 2015;29(2):138-48.

26. Pound CR, Partin AW, Eisenberger MA, Chan DW, Pearson JD, Walsh PC. Natural history of progression after PSA elevation following radical prostatectomy. Jama. 1999;281(17):1591-7.

27. De Giorgi U, Caroli P, Scarpi E, Conteduca V, Burgio SL, Menna C, Moretti A, Galassi R, Rossi L, Amadori D et al. (18)F-Fluorocholine PET/CT for early response assessment in patients with metastatic castration-resistant prostate cancer treated with enzalutamide. Eur J Nucl Med Mol Imaging. 2015;42(8): 1276-83.

28. De Giorgi U, Caroli P, Burgio SL, Menna C, Conteduca V, Bianchi E, et al. Early outcome prediction on 18 F-fluorocholine PET/CT in metastatic castration-resistant prostate cancer patients treated with abiraterone. Oncotarget. 2014;5(23):12448-58.

29. Ceci F, Castellucci P, Graziani T, Schiavina R, Renzi R, Borghesi M, et al. (11)C-Choline PET/CT in castration-resistant prostate cancer patients treated with docetaxel. Eur J Nucl Med Mol Imaging. 2016;43(1):84-91.

30. Soloway MS, Hardeman SW, Hickey D, Raymond J, Todd B, Soloway S, Moinuddin M. Stratification of patients with metastatic prostate cancer based on extent of disease on initial bone scan. Cancer. 1988;61(1):195-202.

31. Miyoshi Y, Noguchi K, Yanagisawa M, Taguri M, Morita S, Ikeda I, Fujinami K, Miura T, Kobayashi K, Uemura H. Nomogram for overall survival of Japanese patients with bone-metastatic prostate cancer. BMC Cancer. 2015;15(1):338.

32. Armstrong AJ, Kaboteh R, Carducci MA, Damber JE, Stadler WM, Hansen M, Edenbrandt L, Forsberg G, Nordle O, Pili R et al. Assessment of the bone scan index in a randomized placebo-controlled trial of tasquinimod in men with metastatic castration-resistant prostate cancer (mCRPC). Urol Oncol. 2014;32(8):1308-16.

33. Dennis ER, Jia X, Mezheritskiy IS, Stephenson RD, Schoder H, Fox JJ, Heller G, Scher HI, Larson SM, Morris MJ. Bone scan index: a quantitative treatment response biomarker for castration-resistant metastatic prostate cancer. J Clin Oncol. 2012;30(5):519-24.

34. Horikoshi H, Kikuchi A, Onoguchi M, Sjostrand K, Edenbrandt L. Computeraided diagnosis system for bone scintigrams from Japanese patients: importance of training database. Ann Nucl Med. 2012;26(8):622-6.

35. Kaboteh R, Damber JE, Gjertsson P, Hoglund P, Lomsky M, Ohlsson M, Edenbrandt L. Bone Scan Index: a prognostic imaging biomarker for high-risk prostate cancer patients receiving primary hormonal therapy. EJNMMI Res. 2013:3(1):9

36. Kaboteh R, Gjertsson P, Leek H, Lomsky M, Ohlsson M, Sjostrand K, Edenbrandt L. Progression of bone metastases in patients with prostate cancer - automated detection of new lesions and calculation of bone scan index. EJNMMI Res. 2013;3(1):64.

37. Kalderstam J, Sadik M, Edenbrandt L, Ohlsson M. Analysis of regional bone scan index measurements for the survival of patients with prostate cancer BMC Med Imaging. 2014;14:24.

38. Poulsen MH, Rasmussen J, Edenbrandt L, Hoilund-Carlsen PF, Gerke O, Johansen A, Lund L. Bone Scan Index predicts outcome in patients with metastatic hormone sensitive prostate cancer. BJU Int. 2015.

39. Smaletz O, Scher HI, Small EJ, Verbel DA, McMillan A, Regan K, Kelly WK, Kattan 23 MW. Nomogram for overall survival of patients with progressive metastatic prostate cancer after castration. J Clin Oncol. 2002;20(19):3972-82.
40. Halabi S, Small EJ, Kantoff PW, Kattan MW, Kaplan EB, Dawson NA, Levine EG, Blumenstein BA, Vogelzang NJ. Prognostic model for predicting survival in men with hormone-refractory metastatic prostate cancer. J Clin Oncol. 2003:21(7):1232-7.

41. Mikkola A, Aro J, Rannikko S, Ruutu M, Finnprostate G. Prognostic grouping of metastatic prostate cancer using conventional pretreatment prognostic factors. Scand J Urol Nephrol. 2009;43(4):265-70.

42. de Bono JS, Oudard S, Ozguroglu M, Hansen S, Machiels JP, Kocak I, Gravis G, Bodrogi I, Mackenzie MJ, Shen L et al. Prednisone plus cabazitaxel or mitoxantrone for metastatic castration-resistant prostate cancer progressing after docetaxel treatment: a randomised open-label trial. Lancet. 2010;376(9747):1147-54.

43. Kantoff PW, Higano CS, Shore ND, Berger ER, Small EJ, Penson DF, Redfern $\mathrm{CH}$, Ferrari AC, Dreicer R, Sims RB et al. Sipuleucel-T immunotherapy for castration-resistant prostate cancer. N Engl J Med. 2010;363(5):411-22.

44. de Bono JS, Logothetis CJ, Molina A, Fizazi K, North S, Chu L, Chi KN, Jones RJ, Goodman OB, Jr., Saad F et al. Abiraterone and increased survival in metastatic prostate cancer. N Engl J Med. 2011;364(21):1995-2005.

45. Scher HI, Beer TM, Higano CS, Anand A, Taplin ME, Efstathiou E, Rathkopf D, Shelkey J, Yu EY, Alumkal J et al. Antitumour activity of MDV3100 in castration-resistant prostate cancer: a phase 1-2 study. Lancet. 2010; 375(9724):1437-46.

46. Dellis A, Papatsoris AG. The economics of abiraterone acetate for castration-resistant prostate cancer. Expert Rev Pharmacoecon Outcomes Res. 2014;14(2):175-9.

47. Parker C, Nilsson S, Heinrich D, Helle SI, O'Sullivan JM, Fossa SD, Chodacki A, Wiechno P, Logue J, Seke M et al. Alpha emitter radium-223 and survival in metastatic prostate cancer. N Engl J Med. 2013;369(3):213-23.

48. Miyoshi Y, Uemura H, Nakamura M, Hasumi H, Sugiura S, Makiyama K, Nakaigawa N, Kishida T, Ogawa T, Yao M et al. Treatment of androgen-independent, hormone-refractory prostate cancer with docetaxel in Japanese patients. Int J Clin Oncol. 2005;10(3):182-6.

49. Tewari A, Raman JD, Chang P, Rao S, Divine G, Menon M. Long-term survival probability in men with clinically localized prostate cancer treated either conservatively or with definitive treatment (radiotherapy or radical prostatectomy). Urology. 2006;68(6):1268-74.

50. Droz JP, Balducci L, Bolla M, Emberton M, Fitzpatrick JM, Joniau S, Kattan MW, Monfardini S, Moul JW, Naeim A et al. Management of prostate cancer in older men: recommendations of a working group of the International Society of Geriatric Oncology. BJU Int. 2010;106(4):462-9.

51. lasonos A, Schrag D, Raj GV, Panageas KS. How to build and interpret a nomogram for cancer prognosis. J Clin Oncol. 2008;26(8):1364-70.

52. Iranikhah M, Stricker S, Freeman MK. Future of bisphosphonates and denosumab for men with advanced prostate cancer. Cancer Manag Res. 2014:6:217-24.

53. Dearnaley DP, Mason MD, Parmar MK, Sanders K, Sydes MR. Adjuvant therapy with oral sodium clodronate in locally advanced and metastatic prostate cancer: long-term overall survival results from the MRC PR04 and PR05 randomised controlled trials. Lancet Oncol. 2009;10(9):872-6.

\section{Submit your next manuscript to BioMed Central and we will help you at every step:}

- We accept pre-submission inquiries

- Our selector tool helps you to find the most relevant journal

- We provide round the clock customer support

- Convenient online submission

- Thorough peer review

- Inclusion in PubMed and all major indexing services

- Maximum visibility for your research

Submit your manuscript at www.biomedcentral.com/submit 